\title{
EL TRABAJO DE ANTONIO CHAMORRO EN EL INSTITUT DU RADIUM DE PARÍS (1938-1952): HORMONAS Y CÁNCER DE MAMA
}

\author{
Ignacio Melgares Moreno \\ Universidad de Granada \\ Email: imelgares@correo.ugr.es \\ ORCID iD: https://orcid.org/0000-0003-4037-2338 \\ Enriqueta Barranco Castillo \\ Universidad de Granada \\ Email: ebc@ugr.es \\ ORCID iD: https://orcid.org/0000-0002-1426-4416
}

Recibido: 3 marzo 2020; Aceptado: 5 febrero 2020

Cómo citar este artículo/Citation: Melgares Moreno, Ignacio; Barranco Castillo, Enriqueta (2021) "El trabajo de Antonio Chamorro en el Institut du Radium de París (1938-1952): hormonas y cáncer de mama", Asclepio, 73(1): p347. https://doi.org/10.3989/ asclepio.2021.13

RESUMEN: El objetivo de este trabajo es visibilizar la relevancia de uno de los personajes que fueron víctimas del exilio científico tras la guerra civil española. Se trata de Antonio Chamorro Daza (Huesa, Jaén, 1903-Banyoles, Girona, 2003), un Profesor Ayudante de Clases prácticas de la Facultad de Medicina de Granada que, sorprendido en Berlín por la sublevación militar, posteriormente fue juzgado por el Tribunal para la Represión de la Masonería y el Comunismo e inhabilitado para el ejercicio profesional en España. Como refugiado político en París, formó parte de una élite de investigadores que volcaron sus esfuerzos en la investigación experimental sobre el origen hormonal del cáncer de mama, basándose en la llamada medicina de laboratorio, con notables hallazgos, reconocidos en el gran número de publicaciones en las que se les tuvo en cuenta. El grupo de trabajo estuvo dirigido por el médico francés Antoine Lacassagne, quien influyó decisivamente en el porvenir de Antonio Chamorro.

PALABRAS CLAVE: Guerra Civil Española; Exilio científico; Institut du radium; Cáncer de mama; Antonio Chamorro Daza.

\section{THE WORK OF ANTONIO CHAMORRO AT THE INSTITUT DU RADIUM, PARIS (1938-52): HORMONES AND BREAST CANCER.}

ABSTRACT: The objective of this work is to make visible the relevance of one of the characters who were victims of scientific exile after the Spanish civil war. This is Antonio Chamorro Daza, an Assistant Professor of Practical Classes of the Faculty of Medicine of Granada, who was surprised in Berlin by the military uprising, was subsequently tried by the Court for the Repression of Freemasonry and Communism and disabled for the professional exercise in Spain. As a political refugee in Paris, he was part of the elite of researchers who turned their efforts into experimental research on the hormonal origin of breast cancer, based on the so-called laboratory medicine, with remarkable findings, recognized in the large number of publications in those that were taken into account. The working group was led by the French doctor Antoine Lacassagne, who decisively influenced the future of Antonio Chamorro.

KEY WORDS: Spanish Civil War; Scientific Exile; Institut du Radium; Breast Cancer; Antonio Chamorro Daza. 


\section{INTRODUCCIÓN}

Gracias a la labor de la Junta de Ampliación de Estudios e Investigaciones Científicas o JAE (1907-1939), la ciencia española, en las primeras décadas del siglo $X X$, había alcanzado niveles equiparables a los europeos, debido al gran número de profesores de todas las disciplinas que viajaron por los diferentes países en los que se estaban llevando a cabo importantes descubrimientos (Otero y López, 2012, p.127). El programa científico y cultural desarrollado por la JAE no sólo representó el proyecto más innovador para España, con la creación de laboratorios, centros de investigación, dotación de becas para estudiar en el extranjero, etc., sino que puso en contacto a los principales pensadores y científicos de España con los de otros países y continentes. En plena Guerra Civil española, el 19 de mayo de 1938, el gobierno franquista decretó el cese de las actividades de la JAE, pero la Junta mantuvo una delegación en Valencia, apoyada por el gobierno legítimo de la República, que posteriormente se trasladó a Barcelona. A lo largo de la guerra civil, muchos de los científicos de la JAE se vieron obligados a abandonar el país ${ }^{1}$, con la consiguiente repercusión sobre el devenir de la ciencia española.

El objetivo principal de nuestro trabajo es difundir la vida y la obra de un pensionado de la JAE, Antonio Chamorro Daza, como contribución a la labor reparadora que se está llevando a cabo con el fin de mejorar el conocimiento del exilio científico español desencadenado tras la sublevación franquista y la instauración de un régimen dictatorial en el país ${ }^{2}$.

Antonio Chamorro ha sido obviado por los historiadores hasta no hace demasiado tiempo (Girón y Barranco, 2010, p. 69). Francisco Guerra, aunque fue uno de los más reconocidos investigadores de la medicina en el exilio republicano (Guerra, 2003), no lo mencionó en su obra, a pesar de que ya se había hablado de la importancia de su trabajo (Barranco, 1987, p. 130) y se habían difundido sendos artículos sobre su vida y su obra (Barranco, 1999, p. 81 y Barranco y cols., 2001, p. 279).

Hemos estructurado esta publicación en tres apartados. En el primero exponemos la formación intelectual y científica de Chamorro, en el segundo sus vicisitudes como exiliado y en el tercero introducimos unas breves notas sobre la actividad investigadora llevada a cabo por Antoine Lacassagne (1884-1971) en el Institut du radium, como preludio a la exposición del papel desempeñado por Chamorro en el programa de cancerización experimental de la mama desarrollado en dicha institución.
Con este trabajo, pretendemos reivindicar la figura de Antonio Chamorro, un investigador pionero en el estudio experimental de la asociación existente entre las hormonas esteroideas, naturales o sintéticas y la aparición de cánceres mamarios.

\section{FORMACIÓN INTELECTUAL Y CIENTÍFICA DE ANTONIO CHAMORRO}

Antonio Chamorro Daza (Huesa 1903-Banyoles 2003), a imitación de sus progenitores, comenzó a los 15 años sus estudios de Magisterio en la Escuela Normal de Maestros ${ }^{3}$ y en 1922, obtuvo el título de bachiller tras serle convalidadas determinadas asignaturas $^{4}$. Después ingresó en la Facultad de Medicina de la Universidad de Granada, donde cursó los estudios de licenciatura y destacó, entre otras, en las asignaturas de Obstetricia y Anatomía Patológica ${ }^{5}$. En la facultad granadina fue discípulo del catedrático de Obstetricia Alejandro Otero Fernández (Redondela 1888-México D.F. 1953), quien, en su asignatura, le otorgó la calificación de Sobresaliente y premio. Licenciado en medicina en el año 1927, en 1928 obtuvo por oposición una plaza de Inspector Municipal de Sanidad ${ }^{6}$ pero no ejerció como tal porque primó en él la pasión por la ginecología y el laboratorio, como nos lo describió el propio Otero:

D. Antonio Chamorro Daza trabaja en mi Clínica oficial y en mi servicio privado desde noviembre de 1928 hasta la fecha como Ayudante y Prof. de Clases prácticas interviniendo con [...] dominio técnico no solo en los trabajos de exploración y operaciones obstétricas y ginecológicas sino además llevando exclusivamente la sección de Radium y Roentgenoterapia y el Laboratorio de la Clínica en su aspecto anatomopatológico, bacteriológico y experimental a plena satisfacción mía. Ha demostrado siempre un gran interés y cariño por todos los problemas de nuestra especialidad y posee un espíritu observador y crítico nada común, revelado en los trabajos de investigación que ha iniciado 7 .

Otero, desde su llegada a Granada, había participado en el proceso de incorporación de la medicina experimental a la Ginecología y la Obstetricia (Olagüe, 2001, p. 66), y Chamorro colaboró con él para divulgar en Granada las novedades que se estaban generando en Alemania y en Estados Unidos sobre el papel desarrollado por la hipófisis en la regulación del ovario y de otras glándulas endocrinas (Girón y Barranco, 2010, p. 69$)^{8}$, y confraternizó con su maestro cuando este se decidió a participar activamente en la política granadina, como veremos en su momento. 
En el año 1932 y, bajo la dirección de Otero, Chamorro inició las investigaciones para su tesis doctoral (Barranco 1987, p. 131), finalmente titulada La trasplantación autoplástica del ovario a la cámara anterior del ojo en la coneja ${ }^{9}$, que fue defendida en la Universidad Central en el año 1935 (Chamorro, 1935, p. 401). En su trabajo, ideó un procedimiento con el que observaba directamente la función del ovario con sólo abrir el ojo del animal en el que este había sido injertado (Chamorro, 1965, pp. 3-5).

Por otra parte, en unos momentos en los que existían muchas dudas sobre la función de la hipófisis en la regulación hormonal, Chamorro, con la colaboración de otros profesores de la Facultad de Medicina de Granada, logró poner a punto una técnica para su ablación en conejas. Fruto de este experimento fue la publicación de un artículo titulado La reacción de embarazo en conejas hipofisectomizadas. Una técnica para la hipofisectomía (Chamorro, 1936, p. 81). Con el tiempo, esta investigación le abrió las puertas de la institución en la que iba a desarrollar la mayor parte de su actividad científica: el Institut du radium (Moreno et. al., 2019, p. 238).

Chamorro concurrió a una convocatoria pública para la obtención de una pensión de la JAE en el año 1934, pero no le fue concedida. En el año 1935 volvió a solicitarla y lo hizo presentando una memoria en la que concretaba sus intereses:

Asistir a un curso pronunciado por Selmar Aschheim sobre las secreciones internas en ginecología, y estudiar en su laboratorio la acción de los extractos hipofisarios sobre los ovarios y las hipófisis y la acción de la hipofisectomía sobre las diferentes fases de la fisiología ovárica. ${ }^{10}$

Esa vez sí le fue concedida la ayuda solicitada y a finales de ese año, cuando estaba a punto de contraer matrimonio en Granada, lo dejó todo y se marchó a Berlín ${ }^{11}$. Una obligación de los pensionados era remitir periódicamente a la dirección de la JAE un informe sobre los trabajos que iban desarrollando, y su primera memoria de actividades la envió en el mes de febrero de 1936. En ella explicaba sus progresos en el Laboratorio de Biología y Anatomía Patológica de la Universitäts Fraüenklinik La Charité (Berlín), donde los profesores Wagner y Aschheim, junto con el doctor Kaufmann, le habían proporcionado facilidades para "desarrollar una labor experimental sobre las hormonas sexuales del lóbulo anterior de la hipófisis". Unos meses más tarde comunicó que la sede central del Laboratorio Schering-Kahlbaum contaba con más medios técnicos y se había desplazado hasta allí para trabajar bajo la dirección de los investigadores Walter Schöeller (18801965), Walter Hohlweg (1902-1992) y Karl Junkmann en la sección de Farmacodinamia y Hormonología ${ }^{12}$.

Siguiendo con el plan de trabajo previsto, en el mes de marzo de 1936, comunicó que había:

[trabajado con] ratas hipofisectomizadas [...] bajo la dirección del Dr. Junkmann en el Hauptlaboratorium de Schering-Kahlbaum, del cual ha aprendido la técnica de la hipofisectomía en ratas13 [...] en el Laboratorio de Biología e Histología de la Univ.-Fraüenklinik Charité [había] comenzado la elaboración de los hormones gonadotropos [investigando en] conejos infantiles y en conejas adultas castradas con ovarios infantiles implantados bajo la cápsula renal14 [utilizando] un material animal de 374 ratas [...] de las cuales 282 [habían] sido hipofisectomizadas ${ }^{15}$.

En el mes de agosto de 1936, cuando España estaba sumida en su conflicto bélico, Antonio Chamorro envió el que sería su último informe dirigido a la $\mathrm{JAE}^{16}$ :

Durante el mes de julio [...] hemos proseguido nuestro trabajo experimental sobre hormones gonadotropos del lóbulo anterior de hipófisis [...] Hemos aprendido con el Dr. Junkmann a practicar hipofisectomías en gallos [...] En colaboración con el Dr. Hohlweg (sic) hemos comenzado un trabajo sobre la acción de la foliculina sobre el tracto genital de ratas infantiles hipofisectomizadas [...] De orina de mujeres castradas hemos preparado extractos con dos diferentes métodos.

Lo más relevante de esta estancia en Alemania, aparte de sus progresos técnicos, fue que Chamorro, dirigido por Hohlweg, estudió el efecto luteinizante de la hormona secretada por el folículo ovárico y su influencia sobre el lóbulo anterior de la hipófisis ${ }^{17}$. El texto definitivo de esta investigación vio la luz bajo el título Über die luteinierende Wirkung des Follikelhormons durch Beeinflussung der luteogenenen Hypophysenvorderlappensekretion (Hohlweg y Chamorro, 1937, p. 196), publicación que ha gozado de un considerable impacto.

\section{ANTONIO CHAMORRO: ACTIVIDAD POLÍTICA Y EXILIO}

Antes de marchar a Alemania, Antonio Chamorro había desempeñado una importante actividad política en la Granada de su época, llegando a desempeñar puestos de responsabilidad en la Agrupación Socialista de la capital, primero como miembro de sus Juventudes y más tarde como vicepresidente de la UGT. Alejandro Otero, siendo presidente de dicha Agrupación, 
durante la celebración de unas elecciones primarias para la presentación de candidatos a diputados a Cortes en 1933, lo promocionó en el quinto puesto de la lista de socios elegibles, pero los electores no le dieron su confianza y optaron por militantes ajenos a Granada, en un acto en el que la influencia de Fernando de los Ríos fue decisiva para la toma de decisiones ${ }^{18}$.

Al igual que muchos otros intelectuales granadinos y profesores de su universidad, Chamorro se inició en el año 1932 en la práctica de la masonería, en la logia Ganivet no 83 de los Valles de Granada. Esta faceta de su vida ha sido igualmente desconocida por los historiadores (Ruiz, 2013, p. 205) ${ }^{19}$.

Como ya hemos comentado, Chamorro viajó a Berlín en el mes de noviembre de 1935, por lo que la sublevación militar en España le sorprendió allí. Aunque recibió instrucciones para que regresara a España, no lo hizo y permaneció en la capital alemana, donde el 3 de noviembre de 1936 sería nombrado secretario interino de la Embajada de España (Barranco y Girón, 2007, p. 51). La situación política en aquél país hizo que ya, a finales de este año, Antonio, se instalara en París, donde prosiguió con la labor diplomática hasta su cese en el mes de agosto de $1938^{20}$.

Tras la interrupción de dicha labor, Chamorro intentó reanudar sus tareas científicas. Según podemos leer en la correspondencia que mantuvo con la británica Maud Denner, quien previamente había residido en Granada y ejercido como traductora, casualmente Chamorro se encontró en París con el médico judío alemán Selmar Aschheim, uno de sus antiguos mentores, que por entonces trabajaba en el parisino hospital de Beaujon, y este le introdujo en el Institut du radium, centro que en marzo de 1938 ya había acogido al médico gallego José Ma Fernández Colmeiro (1894-1959) (Dussaut, 1959, p. 24).

Del encuentro con Aschheim daba cuenta Denner en una carta fechada el 24 de noviembre de 1938:

Qué buenas noticias ha traído su carta! Le felicito sinceramente y me alegro mucho de saber que otra vez está trabajando en la medicina que es su afición y talento. Ya verá - iun día resultará algo grande de sus investigaciones! Además, trabajar con científicos tan distinguidos es gran cosa. Que co-incidencia (sic) más rara la de encontrarse con Aschheim. Yo me acuerdo bien de su nombre y me parece que he visto su nombre en algunos artículos que yo traducí (sic) por U. en Granada ${ }^{21}$.

Su mentor Alejandro Otero, una vez finalizada la contienda en España, permaneció en Francia durante algunos meses y después se exilió en México D.F., y antes de marcharse, intentó que Chamorro viajara hasta allí. Así lo expresó en una carta dirigida al dirigente socialista Francisco Cruz Salido, carta que no llegó a ser entregada a su destinatario porque antes la GESTAPO lo detuvo, junto con Julián de Zugazagoitia y los enviaron a España, para ser juzgados y ejecutados (Barranco y Girón, 2007, p. 68). Tras este fallido intento de salir de Francia, Chamorro trató de exiliarse en el Reino Unido, ayudado por la citada Maud Denner, pero la situación política en Europa lo hizo imposible, según se deduce de las palabras que esta le dirigió en una misiva fechada el 16 de septiembre de $1939^{22}$. Durante el gobierno de Vichy (julio de 1940-agosto de 1944), Chamorro también temió ser detenido (Barranco y Girón, 2006, p. 773), algo frecuente en el ambiente de los refugiados y en el propio Laboratoire Pasteur, hecho del que dejó constancia el propio Fernández Colmeiro (Dussaut, 1959, p. 22). Para alejarse del peligro recurrió a ocultarse durante largas temporadas en las Côtes du Nord ${ }^{23}$.

Tras promulgarse en el año 1939 la Ley de Responsabilidades Políticas, Chamorro fue juzgado en rebeldía por el Tribunal Especial para la Represión de la Masonería y del Comunismo y condenado en 1942:

Como autor de un delito consumado de masonería a la pena de doce años y un día de reclusión menor y accesorias de inhabilitación absoluta perpetua para el ejercicio de cualquier cargo del Estado, Corporaciones públicas y oficiales [...] separándole definitivamente de los aludidos $\operatorname{cargos}^{24}$.

Un año más tarde se iniciaron los trámites para la "incautación de sus bienes" (Gómez, Martínez y Barragán, 2015, p. 35) ${ }^{25}$, pero fue declarado insolvente y el régimen franquista ignoró su paradero. Chamorro permaneció en Francia durante toda su vida, primero como refugiado político y más tarde como "residente privilegiado". Regresó a España en cinco ocasiones, la primera dos años después de la muerte de Franco y la penúltima para visitar Granada en la primavera de 1980, ciudad en la que intentó pasar desapercibido ${ }^{26}$. Pocos días antes de su fallecimiento, hizo su último viaje hasta Banyoles (Girona) acompañado por sus familiares más cercanos.

\section{ANTONIO CHAMORRO EN EL INSTITUT DU RADIUM (PARÍS): APORTACIONES A LA INVESTIGACIÓN SOBRE EL CÁNCER DE MAMA}

Antes de analizar la actividad investigadora de Chamorro en el Institut du radium, consideramos oportuno hacer algunas precisiones. En primer lugar, 
daremos unas breves pinceladas sobre la asociación parisina con la que posteriormente Chamorro se vería muy vinculado. Se trata de la Société de Biologie, fundada en París en el año 1849 y destinada a estudiar:

[...] avec des vues d'ensemble et par les vois de l'observation et de l'expérimentation, les phénomènes qui se rattachent à la science de la vie, à la biologie, tant normale que pathologique (Lebert, 1849, pp. 1-2).

El prestigioso Claude Bernard fue uno de sus dos primeros vice-presidentes. Sus asociados fijaron la celebración de sesiones científicas semanales para que los investigadores comunicaran sus hallazgos cuando eran autorizados por su presidente o su secretario. Posteriormente éstos se publicarían como Comptes Rendus [informes]. En el año 1939 contaba la Société con corresponsales en treinta y tres países y entre ellos se contaban dos españoles, Augusto Pi i Suñer y Pío del Río Hortega ${ }^{27}$. En segundo lugar nos vamos a referir al Laboratoire Pasteur, una dependencia del Institut du radium creado a finales de 1909 y, desde 1914, dirigido por Marie Curie. En dicho laboratorio, tras la finalización de la Primera Guerra Mundial (1914-1918), se investigaría la radiactividad en sus aspectos biológicos, fisiológicos y terapéuticos (Hayter, 1998, p. 665; Chamak, 2004, p. 103; Camillèri y Coursaget, 2005, p. 202; Massiot y Pigeard-Micault, 2016, p. 14). Inicialmente, el Pasteur estuvo dirigido por Claudius Regaud (18701941) y, desde el año 1937, por Antoine Lacassagne (1884-1971) (Del Regato, 1982, p. 2.169). Ambos conformaron el equipo que puso en marcha una línea de investigación oncológica. No es objeto de este trabajo comentar la extensa y productiva actividad investigadora de Lacassagne, por lo que nos vamos a limitar a mencionar dos de sus líneas: la primera, el esclarecimiento de si la etiología del cáncer se asentaba en algún factor celular o endógeno y la segunda, conocer el papel que jugaban las hormonas sexuales femeninas en la génesis de determinados tipos de cáncer, y saber si éstos se podían tratar con antagonistas. Sus investigaciones suscitaron el interés mundial sobre la hormonoterapia y su aplicación en el tratamiento de cánceres hormono dependientes como son el de mama o el de próstata (Latarjet, 1973, p. 50; Chamak, 2004, p. 120).

Como ya hemos comentado, Chamorro comenzó a trabajar en el Pasteur en el mes de septiembre de 1938, cuando Lacassagne ya era uno de los miembros titulares honoríficos de la Société de Biologie. Ante sus socios, Chamorro tuvo la oportunidad y el privilegio de exponer gran parte de los resultados de su actividad investigadora, porque aún siendo un becario extranjero, en el año 1939 pudo hacer sus primeras aporta- ciones y, cuando se encontraba al final de su carrera, todavía lo continuaba haciendo.

Desde el punto de vista laboral, tras una etapa de cierta precariedad, Chamorro fue contratado como investigador en el Centre National de la Recherche Scientifique (CNRS), organización en la que fue ascendiendo de forma reglamentada desde Chargé de Recherche, $3^{e ̀}$ classe (1945-48), Chargé de Recherche $2^{\grave{e}}$ classe (194849), Maître de Recherche $3^{3}$ classe (1949-53), Maître de Recherche $2^{\grave{c}}$ classe (1953-56), hasta Maître de Recherche $1^{\text {ère }}$ classe $(1956-1971)^{28}$.

A pesar de este progreso en el escalafón, Chamorro no se sentía satisfecho con las condiciones laborales que se le imponían, según se puede deducir de la lectura de su correspondencia. Por ella sabemos que, en 1947, cuando el ginecólogo José Luchsinger Centeno se instaló en Venezuela, intentó que Chamorro viajara para investigar allí, algo que no llegó a producirse, aunque desconocemos los motivos (Barranco y Girón, 2007, p. 15). También sabemos que Nicolás Cabrera, en el año 1947, unos meses antes de instalarse en Bristol (U.K.), habló con Ángel Establier Costa (1904-1976), por entonces director del Colegio de España en París, sobre su situación:

Hablé de ti con Establier, que me dijo que fueras a verle. Te envío una tarjeta para él, pero tú te presentarás mejor que yo puedo hacerlo. Un abrazo sincero de buen amigo [rubricado] Nicolás Cabrera [...] Saluda también a Colmeiro, y que siento [...] mucho no despedirme de él ${ }^{29}$.

Chamorro, hasta comienzos de los años 50 del pasado siglo, se dedicó casi exclusivamente al estudio de la patología mamaria en diferentes mamíferos, bajo la dirección de Lacassagne e inmerso en el desarrollo del programa de cancerización experimental que este dirigía. Fruto de esta actividad fue la publicación de un total de 31 artículos científicos, la mayoría en forma de "notas" en les Comptes Rendus, tras ser presentados en las sesiones científicas de la ya citada Société de Biologie ${ }^{30}$.

Nosotros vamos a desgranar aquí los resultados más relevantes de lo publicado por Chamorro en 11 de sus notas, la mayoría destinadas a comunicar los hallazgos encontrados al estudiar la relación entre las hormonas y la aparición del cáncer de mama. El resto de sus publicaciones sobre patología mamaria las presentamos en la tabla 1, para así poder ofrecer una visión de conjunto del interés de Chamorro en desentrañar los mecanismos que regían dicha enfermedad. 
El primer objetivo de Chamorro fue el de investigar el papel de los estrógenos en la aparición de cáncer en las ubres de los ratones, cuando todavía llevaba menos de un año adscrito al Pasteur en calidad de "trabajador técnico y científico en la organización de los nuevos laboratorios" ${ }^{31}$. Presumía que:

[...] si a ratas macho hipofisectomizadas, pertenecientes a una extirpe cancerosa, se les administraba estrógenos y lograba que éstos desarrollaran un carcinoma en sus mamilas, podría demostrar que los estrógenos actuaban directamente sobre las mismas, independientemente de la hipófisis ${ }^{32}$.

Con los resultados obtenidos se presentó por primera vez ante los miembros de la Société de Biologie, en una sesión presidida por Noël Fiessinger el 8 de julio de 1939, y en sus conclusiones destacó que la extirpación de la hipófisis no modificaba la evolución del carcinoma inducido por los estrógenos en la ubre (Lacassagne y Chamorro, 1939, p. 1078) 3. Dos $^{33}$ años más tarde publicó otros hallazgos con los que demostraba que la hipófisis era indispensable para que el ovario secretara hormonas estimulantes del crecimiento mamario (Chamorro, 1941, p. 156) ${ }^{34}$, pero no descuidó su interés en demostrar la influencia de los estrógenos en la carcinogénesis mamaria, especialmente si eran administrados en formulas sintéticas tales como el benzoato de estrona (Chamorro, 1943a, p. 326) ${ }^{35}$. Posteriormente señaló que la evolución de los tumores mamarios espontáneos tampoco se modificaba cuando se extirpaba la hipófisis (Chamorro y Dobrovolskaïa-Zavadskaïa, 1945b, p. 617) ${ }^{36}$.

Ante la sospecha de que otras hormonas sexuales podrían tener un efecto similar al de los estrógenos en el desencadenamiento de alteraciones en las ubres, sucesivamente ensayó con sustancias androgénicas, en principio consideradas como antiestrógenos, pero, como ya advirtió Hans Selye (Selye, 1942, p. 618), se encontró con que en aquel momento era difícil establecer la actividad farmacológica de todas las hormonas esteroideas, y se habían detectado reacciones cruzadas entre ellas. Con esta perspectiva, Chamorro se planteó estudiar la actividad del propionato de testosterona sobre la mama de ratas castradas y observó que ésta era similar a la de los estrógenos (Chamorro, 1945a, p. 589) ${ }^{37}$. También ensayó con otros productos como la pregneninolona o etinil-testosterona ${ }^{38}$, examinando las mamas "in toto" tras el sacrificio de los animales. Observó que ambos productos inducían un rápido crecimiento mamario en animales no hipofisectomizados, pero reconoció que ignoraba el porqué:
Mais comme pour toute la série de substances stimulantes de la mamelle, l'éthinyl-testostérone n'est actif qu'en présence de l'hypophyse [...] Le problème du mécanisme intime de l'action de ces substances excito-mammaires n'est pas éclairci. Nos connaissances sur son métabollisme sont nulles (Chamorro, 1943b, p. $88)^{\prime \prime 39}$.

Como ya hemos comentado, Lacassagne lideraba una línea de investigación basada en la llamada cancerización experimental. En el año 1936 Bittner había demostrado que a través de la leche se transmitía un virus inductor de tumores mamarios en la descendencia (Bittner, 1936, p. 162). Se trataba del conocido en la literatura anglosajona como Mouse Mammary Tumor Virus (MMTV), y en la francesa como facteur-lait. Posteriormente, se demostró que este agente era un retrovirus con una estructura muy similar al de la inmunodeficiencia humana descrito años más tarde por Luc Montagnier (Montagnier, 2002, p. 1727) ${ }^{40}$. Chamorro se basó en el descubrimiento de Bittner para intentar provocar el adenocarcinoma de la ubre en cobayas, insertándoles por vía subcutánea un estrógeno sintético junto con una inyección de facteur-lait. Su objetivo se vio frustrado porque los cobayas se debilitaron y murieron precozmente ${ }^{41}$.

En el año 1943, el conflicto bélico mundial planteó dificultades a la hora de encontrar quien suministrara pienso para la alimentación de los animales de laboratorio, y a los ratones blancos de la raza RIII, predispuestos genéticamente a padecer cáncer de mama, les tuvieron que alimentar con productos con menor contenido en grasas y en proteínas de origen animal. Además, hasta 17 camadas consanguíneas fueron amamantadas por madres afectadas por tumores mamarios sin ser portadoras del citado facteur-lait. Al contrario de lo que se esperaba, la incidencia de cáncer de la ubre en la descendencia bajó desde un 100\% en el año 1939 hasta un 10\% en el año 1944. Para Chamorro, el factor determinante de este descenso fue el cambio introducido en la alimentación de los animales (Chamorro, 1945c, p. 661) ${ }^{42}$.

Recompuesto el equipo investigador del Pasteur tras la finalización de la II Guerra Mundial, y ya como personal contratado por el CNRS, en los años 1947 y 1948 Chamorro colaboró con el equipo clínico que dirigía la consulta de enfermedades de la mama del Hospital Curie. Esto le brindó la oportunidad de diagnosticar y tratar a mujeres afectadas por la enfermedad de Reclus, un proceso patológico de la mama caracterizado por la aparición en la misma de múltiples quistes de pequeño tamaño, asociados al desarrollo de tejido fibroso, y por ello, también denominado "mastopatía 
fibroquística" (Klingenstein, 1935, p. 1144). Chamorro había observado que las ratas y ratones afectadas por carcinomas de la ubre previamente habían padecido procesos similares a esta mastopatía, atribuibles a un exceso absoluto o relativo de secreción estrogénica y el consiguiente déficit de progesterona ${ }^{43}$.

Sospechando que la enfermedad de la glándula tiroidea podría estar relacionada con la aparición de la enfermedad de Reclus, sola o asociada con otras patologías glandulares, se dispuso a investigarlo y aportó sus resultados en cuatro publicaciones:

1. Influence de la thyroïde et de la surrénale dans la stimulation mammaire par la sécrétion ovarienne: en la rata hembra adulta, con la extirpación del tiroides se provocaba una hipertrofia mamaria si antes no se habían extirpado los ovarios (Chamorro, 1946, p. $500)^{44}$.

2. Production expérimentale chez les rats femelles de nodules d'hyperplasie kystique de la mamelle sous l'influence de faibles doses d'une substance anti-thyroïdienne: con dosis bajas de propil-tiouracilo, un fármaco utilizado para aminorar la secreción de hormonas tiroideas en ratas hembras, se desencadenaba la aparición de nódulos de hiperplasia quística en la ubre (Chamorro, 1948a, p. 428) ${ }^{45}$.

3. Production d'hyperplasie kystique de la mamelle chez le rat femelle adulte, par thyroïdectomie: entre 6 y 8 semanas después de extirpar el tiroides en las ratas adultas se observaban adenomas e hiperplasia quística de la ubre (Chamorro, 1948b, p. 353) ${ }^{46}$.

3. Rôle de la thyroïde dans la production, par les substances oestrogènes, d'hyperplasie kystique de la mamelle, chez des rats: demostró que con la administración de hormona tiroidea (tiroxina) se impedía la aparición de la ya comentada hiperplasia quística en la ubre (Chamorro, 1949, p. 226) ${ }^{47}$.

Es significativo que algunos de los trabajos de investigación realizados por Chamorro durante su etapa de colaborador en la clínica nunca llegaran a ver la luz, lo que indicaba que, mientras le era fácil comunicar resultados de laboratorio, no lo era tanto cuando éstos eran clínicos. Este fue el caso de sus observaciones sobre la existencia de una enfermedad tiroidea subyacente, generalmente un hipotiroidismo, en los casos de mastopatía fibroquística femenina, y su remisión tras prescribir tiroxina a las pacientes afectadas por dicha enfermedad ${ }^{48}$.

Como reconocimiento a su amplia experiencia en la patología experimental de la mama, Chamorro fue
Foto 1: Fotografía de juventud de Antonio Chamorro (donación de la familia Chamorro López-Quiñones).

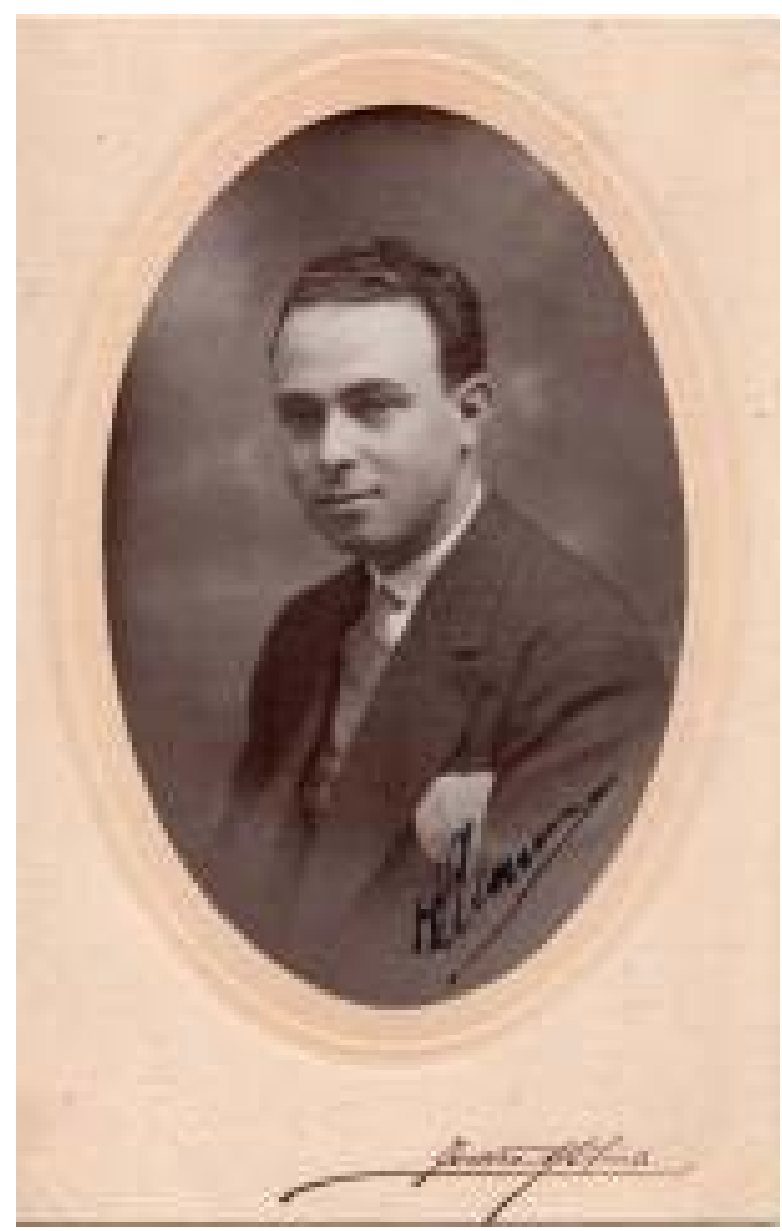

invitado a participar como ponente en $51^{e}$ Congrès Français de Chirurgie, organizado por l'Association Française de Chirurgie y que fue celebrado en París en 1948. Su ponencia sobre el tratamiento hormonal del cáncer de mama posteriormente se tradujo al alemán y se publicó en la revista Strahlentherapie, insistiendo en que ni las hormonas ni la castración eran capaces de curar dicha afección (Chamorro, 1950, p. 440).

Y el colofón a esta etapa fue la invitación que recibió para participar en un encuentro científico que se iba a celebrar en Londres del 10 al 13 de julio de $1950^{49}$, en la sede de The Ciba Foundation (41 Portland Place, London), y en el mismo se discutieron "los efectos de las hormonas esteroideas y otros compuestos relacionados sobre el crecimiento tumoral". ${ }^{50} \mathrm{El}$ presidente de este encuentro fue Alex Haddow, un investigador del Chester Beatty Research Institute (Londres). Cuarenta investigadores de diferentes países se dispusieron a intercambiar información sobre las hormonas esteroideas en el seno de la citada reunión. La 
Foto 2: Jardines del Pavillon Pasteur. Graffiti con la imagen de Antoine Lacassagne (archivo privado de Enriqueta Barranco).

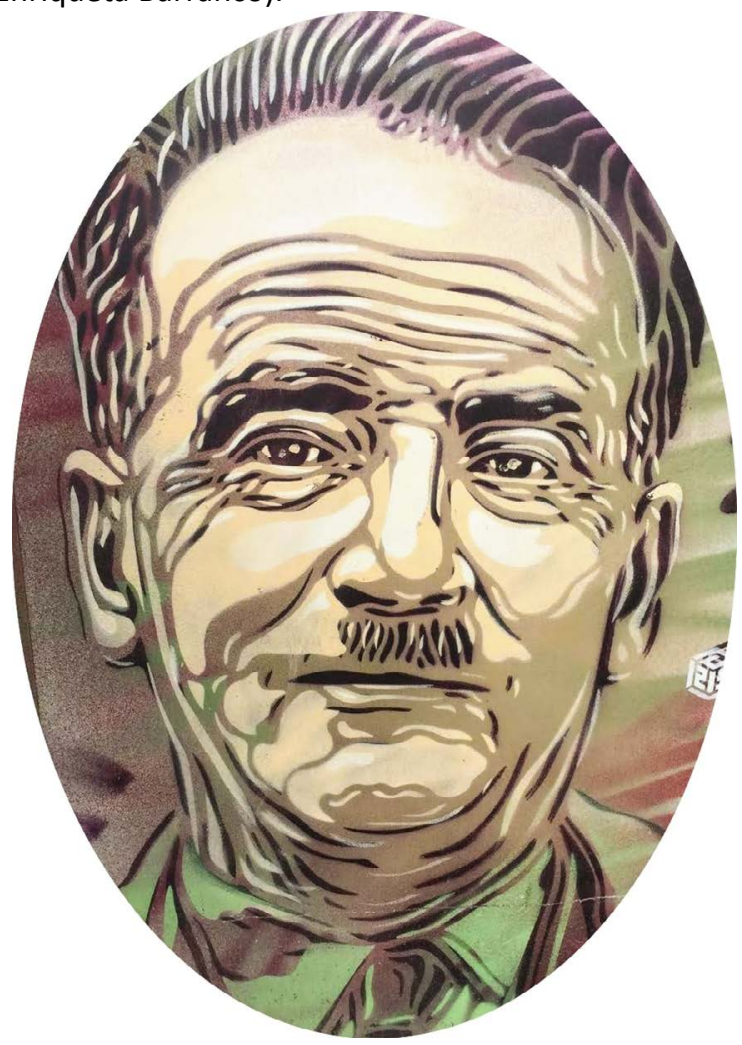

intervención de Chamorro estuvo precedida por la de Samuel J. Folley, director del Departamento de Fisiología del National Institute for Research in Dairying, Shinfield, Reading (U.K.), quien disertó sobre los efectos de los esteroides sobre la mama (Folley, 1952, p. 69) y después Chamorro explicó sus trabajos sobre el papel desempeñado por las hormonas esteroideas en el desarrollo normal y patológico de la mama (Chamorro, 1952, p. 87). Su disertación fue muy bien acogida por los asistentes, la mayoría expertos en el tema, como quedó demostrado en el coloquio que se mantuvo después de la misma.

El botón de oro le llegó a Chamorro a través de l'Académie Nationale de Médecine (París), organización que ya en el año 1949 había instituido el premio Monthus-Menière, destinado a reconocer al autor o autores "de una publicación o trabajo sobre el tratamiento médico del cáncer". La primera edición de este galardón se convocó en el año 1952 y en el listado de aspirantes se encontraba:
“M[onsieur]. Chamorro. 12, passage Cottin, à Paris $(\mathrm{XVII})$ : Travail sur la pathogénie du cancer de la mamelle".

El jurado constituido para la evaluación de los trabajos presentados a dicho premio acordó que la ganadora era la memoria que llevaba por título Experiences sur les facteurs endocriniens intervenant dans la pathogenie de la maladie kystique et de l'adenocarcinome mammaires, realizada por Chamorro:

L'Académie décerne le Prix à M[onsieur]. le Dr. Chamorro, de Paris, pour son travail sur la pathogénie du cancer de la mamelle ${ }^{51}$.

La concesión de este galardón le fue comunicada el día 8 de noviembre de 1952, en una carta del secretario perpetuo de l'Académie:

J'ai I'honneur de vous faire savoir que l'Académie Nationale de Médecine vous a attribué le Prix Monthus-Menière de Médecine pour votre travail sur la pathogénie du cancer de la mamelle, que vous avez bien voulu lui soumettre.

Vous seré avisé, le moment venu, par les soins de $M$. le Ministre de l'Education Nationale, de l'époque à laquelle la somme de DOUZE MILLE FRANCS (12.000 F.) représentant les arrérages de ce prix, sera ordonnacée á votre nom.

Veuillez agréer, Monsieur et cher Confrère, avec mes félicitations particulières, l'assurance de ma considération la plus distinguée ${ }^{52}$.

En la relación de aspirantes al premio Monthus-Menière también figuraba su amigo y compañero José $\mathrm{M}$ a Fernández Colmeiro ${ }^{53}$, quien concursaba con el trabajo Traitement des affections canceréuses pour les rayons $X$, pero este fue galardonado con el premio Chevillon (Dussaut, 1959, p. 25).

Como si la concesión del Monthus-Menière significara el final de un período, a partir de 1952 Antonio dirigió su mirada hacia otras áreas de interés, que también siguieron suscitando la atención de la comunidad científica. En el año 1964, el Institut du Radium creó la Médaille Lacassagne, para otorgársela a los investigadores que hubieran destacado en alguno de los ámbitos en los que allí se trabajaba y Antonio Chamorro fue uno de sus primeros galardonados (Barranco y Girón, 2007, p. 88).

Las repercusiones de los hallazgos científicos de Antonio Chamorro fueron considerables. A través de Google Scholar, Scopus y PubMed hemos podido acceder al impacto bibliométrico de sus artículos sobre 
patología mamaria y hemos encontrado que, al menos, se cuentan 106 referencias a los mismos, lo que supone una media de 3.41 citas por artículo y un índice $h=5$. Se debería tener en cuenta el número de libros, artículos, comunicaciones y ponencias en las que fueron referenciados, algunos de ellos en publicaciones prestigiosas, también con un elevado índice de impacto, algo que será objeto de futuras publicaciones.

\section{CONCLUSIONES}

Antonio Chamorro formó parte de la elite de científicos españoles obligados a trabajar en otros países, porque las sentencias dictadas tras la aplicación de las leyes franquistas le condenaron al exilio.

Durante su etapa de formación, cuando se incorporó como profesor ayudante de clases prácticas a la cátedra de Obstetricia de la facultad de medicina de Granada, en la misma ya se estaba configurando un equipo investigador, dirigido por Alejandro Otero, basado en las técnicas más avanzadas. Con la pensión de la JAE tuvo la oportunidad de viajar a Berlín, centro neurálgico en aquél momento de la metodología experimental y de la investigación en síntesis hormonal, con el ánimo de trasladar después estos conocimientos a Granada. Sin embargo, los acontecimientos políticos no sólo se lo iban a impedir sino que además le conducirían a la deriva en el ámbito científico. Afortunadamente, pudo remediar de alguna manera su incierta situación como refugiado político ingresando en una institución parisina altamente consolidada, el Institut du Radium y su Laboratoire Pasteur.

La tranquilidad personal y científica iba a durar poco, pues rápidamente Francia entraría en guerra, y casi la mitad de la actividad científica de Antonio Chamorro, entre 1938 y 1952, fue llevada a cabo en una situación precaria personal e institucional, algo que a nuestro parecer tiene un valor añadido, dada la escasa seguridad que la Francia ocupada le podía brindar a un refugiado español.

\section{NOTAS AL FINAL}

1 En: http://www.jae2010.csic.es/historia.php [consultada el 12 de enero de 2021]

2 Para más información ver: "Generaciones de Plata", sobre texto de Barranco y Girón. En: https://generacionesdeplata. fundaciondescubre.es/cientificos/antonio-chamorro-daza/ [consultada el 12 de enero de 2021]

3 Archivo Histórico de la Universidad de Granada (AHUG). Sign. 05187_002_01.
Hemos presentado una selección de las investigaciones llevadas a cabo por Chamorro en las que, basándose en la metodología experimental, logró analizar y describir los efectos de las diferentes hormonas esteroideas sobre la patología mamaria, tratando de identificar los factores responsables del desarrollo de procesos tumorales y no tumorales en las mamas. Entre ellas destacamos las relacionadas con la administración de hormonas sintéticas a los animales de laboratorio y la observación de sus consecuencias, lo que le permitió que sus resultados no pasaran desapercibidos para la comunidad científica de su tiempo, como se demuestra por el índice de citaciones que sigue acumulando, tanto en Google Scholar como en Scopus o en PubMed, a pesar de ser el francés la lengua vehicular de la mayoría de sus publicaciones.

La importancia de su labor investigadora le fue reconocida al ser uno de los pocos científicos españoles que tuvieron la oportunidad de comunicar sus resultados en las sesiones de la Société de Biologie de París, ante especialistas de reconocido prestigio en diferentes áreas, así como de publicar en su órgano oficial.

En el mismo sentido, podemos considerar la concesión del premio Monthus-Menière por l'Académie Nationale de Médecine, y con el que le recompensaron su interés por desvelar los factores desencadenantes de las enfermedades de la mama, pues fue un pionero en el descubrimiento de la asociación entre las hormonas estrogénicas, naturales o sintéticas, y la aparición de cánceres de la ubre en los animales de experimentación.

La historia de la ciencia española debería incorporar la obra de Antonio Chamorro a su acerbo. Nuestro trabajo es una contribución al conocimiento de una época en la que la política lastró el desarrollo científico del país.

\section{AGRADECIMIENTOS}

Agradecemos a Mikel Astrain, Fernando Girón y Rosa Ma Moreno sus sugerencias para la redacción definitiva de este trabajo. Sin la colaboración de Alain Poussard y de Isaac Borja Araujo Figueroa nuestras fuentes estarían incompletas.

4 AHUG. Sign. 02072_038_04.

5 AHUG. Sign. 02072_038_01.

6 Gaceta de Madrid, 25/4/1928.

7 AC. Sign. C-99. Certificado ológrafo emitido por Alejandro Otero sobre la actividad profesional de Chamorro.

8 AC. Sign. C. Como ejemplo contamos con el guion de la conferencia pronunciada por Chamorro con el título La hipófisis en la vida sexual de la mujer (c.a. 1930). 
9 Disponemos del ejemplar de la Revista Española de Obstetricia y Ginecología en la que aparece esta publicación, y en ella no se especifica si se trataba de un resumen o del texto íntegro de la tesis.

10 AC. Sign. C-98.

11 AC. Sign. C-95-2. 6/7/1935. Desde la subsecretaría de universidades le comunicaron la concesión de una pensión de 425 pesetas oro mensuales y 600 para viajes de ida y vuelta (Barranco y Girón, 2007, p. 47).

12 AC. Sign. C-95-2. Informe mensual de las actividades llevadas a cabo por Chamorro en Berlín; AC. Sign. C-52. Memoria fechada en Berlín el 10/2/1936, donde afirmaba que estaba investigando junto a prestigiosos profesionales como Wagner, Aschheim, Kauffman y Hohlweg. Muchos años después, en 1953, Hohlweg todavía intercambiaba correspondencia con Chamorro.

13 AC. Sign. C-135. Cuaderno con anotaciones personales de Chamorro y resultados de sus investigaciones.

14 AC. Sign. C-96-5, C-96-7 y C-135. Cuaderno ológrafo con anotaciones sobre las Conejas adultas castradas con ovario infantil trasplantado bajo la cápsula renal entre 1/11/1935 y $28 / 7 / 1936$

15 AC. Sign. C-135. Cuaderno ológrafo sobre los trabajos con Extractos hipofisarios y Prolan.

16 AC. Sign. C-96-12. A pesar de que el gobierno franquista disolvió la JAE en 1938 y, aunque el gobierno legítimo la procuró mantener en Valencia, en los archivos consultados no hemos encontrado ninguna memoria de los pensionados a partir del año 1935.

17 AC. Sign. C-135.

18 Esta información está disponible en: http://www. todoslosnombres.org/content/biografias/antonio-chamorro-daza

19 Este autor dio como desaparecido a Chamorro a partir del año 1942, pero su afirmación no era cierta, si bien desde el Juzgado habían comunicado que se encontraba en ignorado paradero.

20 Gaceta de la República, 5/8/1938, p. 556.

21 AC. Correspondencia personal.

22 AC. Correspondencia personal.

23 AC. Correspondencia personal. En una carta fechada el 17 de octubre de 1942 se dejaba sentir la preocupación de sus compañeros tras una larga estancia en aquella región, cuando no regresó a su puesto de trabajo y Fernández Colmeiro acudió a buscarlo a su alojamiento y no lo encontró.

24 CDMH/TERMC, Ficheros: 70,2206360;74,2404405; 77,2707131. BOE, 13 de enero de 1943, p. 145.

25 Archivo de la Real Chancillería de Granada. Leg. 25.981, pieza 15. Una vez dictada la sentencia, desde el Tribunal Especial para la Represión de la Masonería y el Comunismo se emitió una orden para que la Audiencia Provincial de Granada adoptara "las medidas precautorias para el aseguramiento de los bienes" de Chamorro. La orden fue derivada al Juzgado de Instrucción de Guadix, en donde el 7 de julio de 1943 señalaron que el encausado "es insolvente y se haya en ignorado paradero, por cuyo motivo no se han podido adoptar medidas precautorias de aseguramiento de bienes".

26 AC. Anotaciones peronales de Andrée Jacob.
27 En: https://gallica.bnf.fr/ark:/12148/bpt6k9759136n?rk=64378;0 [consultado el 10/12/2019]

28 AC. Sign. C-203 y 204-6.

29 AC. Correspondencia personal.

30 Esta comunidad científica recibió a Chamorro el día 8 de julio de 1939, nueve meses después de su entrada en el Pasteur, y fue presentado por Lacassagne.

31 A.C. Vida laboral de Antonio Chamorro.

32 AC. Sig. S-1 y S-2. Adaptado del francés por E. Barranco.

33 Gran parte de las separatas de las publicaciones de Chamorro se conservan en AC. Les Comptes Rendus están disponibles en: https://gallica.bnf.fr/ark:/12148/cb34349272v/ date [consultado 10/12/2019]

34 Sesión de la Société de Biologie (en adelante

SB) del 22 de febrero de 1941, presidida por Armand-Delille, y en la que presentó microfotografías de las glándulas mamarias.

35 Sesión de la SB del 26 de junio de1943, presidida por Noel Fiessinger.

36 Sesión de la SB del 7 de julio de 1945, presidida por Marcelle Lapicque.

37 Sesión de la SB del 23 de junio de 1945, presidida por Léon Launoy. El primer trabajo presentado en esta sesión trataba de la hipofisectomía, y disertó sobre el mismo Georges Bourguignon, del hospital de La Salpétriére.

38 A.C. Sign. S-3.

39 Sesión de la SB del 13 de febrero de 1943, presidida por Paul Portier. Apenas hacía unos meses desde que Hans Selye describiera la farmacología de los esteroides y sus derivados (Selye, 1942). Descubrimientos nada sorprendentes si tenemos en cuenta que durante la degradación metabólica dichas substancias terminan convirtiéndose en una molécula estrogénica.

40 Años más tarde, Luc Montagnier y sus colaboradores emprendieron unas investigaciones sobre este tema y finalmente terminaron con la identificación del retrovirus responsable de la inmunodeficiencia humana.

41 Chamorro, Antonio (1952). Ensemble de travaux. Archives et manuscrits de la Bibliothèque de l'Académie nationale de médecine. En: http://www.calames.abes.fr. [consultada el 20/12/2019]. Según el autor algunos de estos trabajos quedaron inéditos.

42 Chamorro presentó los resultados de este estudio en la $S B$ el 21 de julio de 1945, bajo la presidencia de Léopold Nègre, a quien cabe recordar por haber sido pionero en poner a punto la vacunación antituberculosa.

43 Chamorro, Antonio (1952). Ensemble de travaux. Archives et manuscrits de la Bibliothèque de l'Académie nationale de médecine. En: http://www.calames.abes.fr [consultada el 20/12/2019]

44 Trabajo presentado en la sesión de la $S B$ el 20 de julio de 1946, bajo la presidencia del zoólogo Maurice Caullery, quien por entonces ocupaba también la presidencia de dicha sociedad.

45 Comunicación presentada en la sesión de la $S B$ del 10 de abril de 1948, presidida por J. Baudouin. 
46 Antonio Chamorro acompañaba esta publicación con llamativas microfotografías realizadas por él y en las que se visualizaban los cambios histológicos de la mama.

47 Sesión de la SB del 26/2/1949, presidida por el zoólogo Maurice Caullery.

48 AC. Sign. C-162. Correspondencia científica.

49 AC. Sign. B-24, A6/203-224. Para facilitar este viaje, Lacassagne tuvo que dirigirse a la policía francesa, en una nota del $3 / 7 / 1950$, dirigida al prefecto de la misma (París) en la que señalaba: Le docteur Chamorro-Daza, Antonio qui travaille dans mon laboratoire depuis plusieurs années dot se rendre à Londres pour assister à une conférence sur "Les Hormones stéroïdes et la Croissance tumorale", afin d'y présenter une communication sur des travaux reálisés dans mon laboratoire. Cette conférence ayant lieu les 10, 11 et 12 de ce mois, je me permets de vous demander instamment de lui donner toutes facilités por son voyage aller et retour. No olvidemos que Chamorro seguía siendo un refugiado político y estaba en proceso de búsqueda y captura.

\section{BIBLIOGRAFÍA}

Barranco Castillo, Enriqueta (1987), La obstetricia y la ginecología en la Granada de entreguerras. La escuela de Alejandro Otero (1914-1936) (tesis doctoral), Granada, Universidad de Granada, pp. 130, 131 y 171.

Barranco Castillo, Enriqueta (1999), "Científicos españoles en el exilio: Antonio Chamorro (I)", Investigación Clínica, 2 (1), pp. 81-88.

Barranco Castillo, Enriqueta; García Vera, E. (2001), “Científicos españoles en el exilio: Antonio Chamorro (II)", Investigación Clínica, 4 (3), pp. 279-284.

Barranco Castillo, Enriqueta; Girón Irueste, Fernando (2006), Alejandro Otero, Granada, CajaGranada, p. 773.

Barranco Castillo, Enriqueta y Girón Irueste, Fernando (2007), Antonio Chamorro Daza (1903-2003). Un investigador español en el exilio, Granada, Universidad de Granada, pp. 15, 51, 68, 88.

Bittner, John Joseph (1936) "Some possible effect of nursing on the mammary gland tumor incidence in mice" Science, 84 (2172), p. 162

Camillèri, Jean-Pierre y Coursaget, Jean (2005), Pionniers de la radiothérapie, Paris, EDP Sciences, p. 202.

Chamak, Brigitte (2004), "Un scientifique pendant l'Occupation: Le cas d'Antoine Lacassagne", Revue d'histoire des sciences, 57(1), pp. 101-133, pp. 103,120. [en línea] doi: 10.3406/ rhs. 2004.2205

Chamorro, Antonio (1935), "La trasplantación autoplástica de ovario a la cámara anterior del ojo en conejas", Rev. Esp. Obst. Gin., 20 (239), pp. 401-432, p. 401.

Chamorro, Antonio (1936), "La reacción de embarazo en conejas hipofisectomizadas. Una técnica para la hipofisectomía", Rev. Esp. Obst. Gin., 21 (243), pp. 81-86, p. 81.

Chamorro, Antonio (1941), "Sur l'origine ovarienne de substances stimulant la mamelle". Compt. Rend. Soc. biol., 135 (1), pp. 153-156, p. 156.
50 AC. Sign. C-30. The effects of steroid hormones and related compounds on tumour growth. Programa de actos.

51 Bulletin de l'Académie nationale de médecine (1952), nn. 9-10, $3^{\mathrm{e}}$ serie, 136, pp.141-143.

52 AC. Correspondencia personal.

53 AC. Correspondencia personal. Se cuenta con una carta escrita en 1948 (Montevideo), en la que Fernández Colmeiro le comunicaba a Chamorro: “.... Voy a dar dos [conferencias] sobre la etiología del cáncer de mama y hablaré algo también de hormonoterapia. Quisiera que V. me dijese si puedo hablar algo de las cosas que hacíamos ahí, o cuando menos que me diga lo que no debo decir... dígame también como van las mamas, si la perspectiva era como cuando yo estaba ahí o si es mejor". Según Dussaut, Fernández Colmeiro había sido invitado por el Instituto de Radiología de Montevideo para dar conferencias y cursos sobre temas de su especialidad (Dussaut, 1959 p. 25).

Chamorro, Antonio (1943a), "Production par le benzoate d'oestrone d'adéno-carcinome mammaire chez des rats", Compt. Rend. Soc. biol., 137 (1), pp. 325-326, p. 326.

Chamorro, Antonio (1943b), “Action de l'éthinyl-testostérone sur la glande mammaire”, Compt. Rend. Soc. biol., 137 (1), pp. 86-89, p. 88.

Chamorro, Antonio (1945a), "Hormones stéroïdes mammogènes et hyperplasie kystique de la mamelle", Compt. Rend. Soc. biol., 139 (1), pp. 587-589, p. 589.

Chamorro, Antonio; Dobrovolskaïa-Zavadskaïa, Nadine (1945b), "L'action de l'hypophysectomie sur l'adéno-carcinome mammaire spontané de la souris", Compt. Rend. Soc. biol., 139 (1), pp. 614-617, p. 617.

Chamorro, Antonio (1945c), "Diminution de la fréquence d'apparition de l'adéno-carcinome mammaire dans une lignée de souris sujette à cette tumeur", Compt. Rend. Soc. biol., 139 (1), pp. 660-661, p. 661.

Chamorro, Antonio (1946), "Influence de la thyroïde et de la surrénale dans la stimulation mammaire par la sécrétion ovarienne", Compt. Rend. Soc. biol., 140 (1), pp. 499-500, p. 500.

Chamorro, Antonio (1948a), "Production expérimentale chez les rats femelles de nodules d'hyperplasie kystique de la mamelle sous l'influence de faibles doses d'une substance anti-thyroïdienne", Compt. Rend. Soc. biol., 142 (1), pp. 426-428, p. 428.

Chamorro, Antonio (1948b), "Production d'hyperplasie kystique de la mamelle chez le rat femelle adulte, par thyroïdectomie", Ann. Endocrinol., 9 (4), pp. 350-353, p. 353.

Chamorro, Antonio (1949), "Rôle de la thyroïde dans la production, par les substances oestrogènes, d'hyperplasie kystique de la mamelle, chez des rats", Compt. Rend. Soc. biol., 143 (1), pp. 225-226, p. 226.

Chamorro, Antonio (1950), “Die hormonelle Behandlung des Brustkrebses", Strahlentherapie, 83 (3), pp. 437-440, p. 440. 
Chamorro, Antonio (1952), "Le rôle des hormones stéroïdes dans la croissance normale et pathologique de la glande mammaire". En: Wolstenholme, Gordon Ethelbert Ward (ed.), Ciba Foundation Colloquia on Endocrinology, I, Steroid Hormones and Tumour Growth and Steroid Hormones and Enzymes. London, J. \& A. Churchill Ltd., pp. 87-111, p. 87.

Del Regato, Juan Angel (1986), "Antoine Lacassagne”, International Journal of Radiation, Oncology, Biology and Physiology, 12 (12), pp. 2165-2173, p. 2169, [en línea] doi: 10.1016/0360-3016(86)90016-7.

Dussaut, Alejandro (1959), José María Fernández Colmeiro. Su vida y su obra, Conferencia pronunciada el 15 de agosto de 1959 en el homenaje tributado por el Ateneo Pi y Margall, Sección Cultural del Centro Republicano Español, Buenos Aires, Consejo de Galicia, pp. 22, 24, 25.

Folley, S. John (1952), "Some effects of steroids on the mammary gland". En: Wolstenholme, G. E. W. (ed.), Ciba Foundation Colloquia on Endocrinology, I, Steroid Hormones and Tumour Growth and Steroid Hormones and Enzymes. London, J. \& A. Churchill Ltd., pp. 69-86, p. 69.

Girón Irueste, Fernando; Barranco Castillo, Enriqueta (2010), "Dos ginecólogos en el exilio: Alejandro Otero Fernández y Antonio Chamorro Daza". En: Barona, Josep Lluis (ed.), EI exilio científico republicano, Valencia, Universitat de Vàlencia, pp. 67-87, p. 69.

Gómez Oliver, Miguel; Martínez López, Fernando; Barragán Moriana, Antonio (coord.) (2015), El botín de guerra en Andalucía. Cultura represiva y víctimas de la Ley de Responsabilidades Políticas, 1939-1945. Madrid, Biblioteca Nueva S.L., p. 35.

Guerra, Francisco (2003), La medicina en el exilio republicano, Madrid, Universidad de Alcalá.

Hayter, Charles R.R. (1998), "The clinic as laboratory: The case of radiation therapy, 1896-1920", Bulletin of the History of Medicine, 72 (4), pp. 663-688, p. 665.

Hohlweg, Walter; Chamorro, Antonio (1937), “Uber die Luteinierende Wirkung des Follikelhormons Durch Beeinflussung der luteogenen Hypophysenvorderlappensekretion", Klin. Wochens., 16 (6), pp. 196-197, p. 196. [en línea] doi: 10.1007/BF01784226
Klingenstein, P. (1935), "Cystic disease of the breast", Ann. Surg 101(5), p.1144.

Lacassagne, Antoine; Chamorro, Antonio (1939), “Conséquences de I'hypophysectomie chez des souris sujettes au carcinome mammaire, traitées par hormone oestrogène", Compt. Rend. Soc. de biol., 131 (2), pp. 1077-1078, p. 1078.

Latarjet, Raymond (1973), "Notice sur lavie et les travaux de Antoine Lacassagne (1884-1971)", Notices et discours, Académie des Sciences de Paris, 6 (8), pp. 50-59, p. 50

Lebert, M. (1849), Compt. Rend. Soc. de biol, pp. 1-2, p. 1.

Montagnier, Luc (2002), "A History of HIV Discovery", Science, 298, pp. 1727-1728, p. 1727.

Moreno Rodríguez, Rosa Mạa; Melgares Moreno, Ignacio; Barranco Castillo, Enriqueta; Girón Irueste, Fernando (2019), "Antonio Chamorro en la Facultad de Medicina de Granada: el legado científico de un exiliado". En: Gil, Mari Karmen; Zabala, José Ramón (coords.), Científicos y científicas en el exilio de 1936-1939, Donostia, Hamaika Bide Elkartea, pp. 233-240, p. 238.

Olagüe de Ros, Guillermo (2001), Sobre sólida roca fundada: Ciento veinte años de labor docente, asistencial e investigadora en la Facultad de Medicina de Granada (1857-1976), Granada, Universidad de Granada, p. 66.

Otero Carvajal, Luis; López Sánchez, J. M. (2012), La Lucha por la modernidad. Las ciencias naturales y la Junta para la Ampliación de Estudios, Madrid, Consejo Superior de Investigaciones Científicas, p. 127.

Pigeard-Micault, Natalie; Massiot, Anaïs (2016), Les coulisses des laboratoires d'autrefois: Vies et métiers à I'Institut du radium et à la Fondation Curie, Paris, Glyphe, p. 14.

Ruiz Sánchez, José Leonardo (2013), La masonería en Granada en la primera mitad del siglo XX, Sevilla, Secretariado de Publicaciones de la universidad de Sevilla, p. 205.

Selye, Hans (1942), "The pharmacology of steroid hormones and their derivations", Revue Canadienne de Biologie, 1 (6), pp. 577-632, p. 618 